INNOVATIONS IN PRIMARY CARE

\title{
A Change Model for GPs Serving Deprived Areas
}

David N. Blane, Petra Sambale, Andrea E. Williamson, Grabam C.M. Watt

Ann Fam Med 2017;15:277. https://doi.org/10.1370/afm.2064.

\section{THE INNOVATION}

The General Practitioners at the Deep End Pioneer Scheme is an initiative funded by the Scottish Government to develop and establish a change model for general practices serving very deprived areas. The scheme involves the recruitment of younger GPs (or fellows), the retention of experienced GPs, and their joint engagement in strengthening the role of general practice as the natural hub of local health systems. A key component of the scheme is protected time for both early-career and experienced GPs for professional and service development.

\section{WHO \& WHERE}

General Practitioners at the Deep End (http://www.gla.ac.uk/ deepend) are the GPs in the 100 general practices serving the most socioeconomically deprived populations in Scotland (Supplemental Appendix 1). In 2016, The Scottish Government launched a GP recruitment and retention fund in response to the "GP crisis" brought about by increasing demands on general practice (aging population, more complex multimorbidity) and difficulties recruiting and retaining GPs, particularly in rural areas and areas of high socioeconomic deprivation. GPs at the Deep End successfully bid for funding to set up the Pioneer Scheme in 6 practices in Glasgow.

\section{HOW}

After a competitive application process, 6 practices were selected as host practices for 6 Deep End GP fellows, who were also competitively appointed. Each practice has a lead GP for the project who has protected time each week to engage with service development work and attend meetings related to the Pioneer scheme. The 6 practices work together to share ideas

Conflict of interest: authors report none.

\section{CORRESPONDING AUTHOR}

Dr David N. Blane

General Practice and Primary Care

1 Horselethill Road

University of Glasgow, G12 9LX

David.blane@glasgow.ac.uk and learning, and an overall lead GP for the scheme coordinates the activity.

The fellows work 4 days a week, with 3 days in practice and 1 day of protected time to be used in alternate weeks for service development work (collaborating with the lead GP for the practice) and professional development, via a program of day-release sessions with a curriculum based on identified learning needs for Deep End practitioners. ${ }^{1}$ An academic coordinator organizes these day-release sessions and supports the fellows in producing written outputs for wider dissemination. The lead GPs for each practice meet every 6 to 8 weeks and share documents online using http://www.trello.com. There is also a Pioneer Scheme Steering Group, including representatives from Scottish Government and the Health Board.

\section{LEARNING}

General practice in Scotland is in a transitional period, with a new GP contract under negotiation and the removal of the pay-forperformance Quality and Outcome Framework. GP clusters have been introduced as the new mechanism for promoting quality. The Pioneer scheme practices have formed a non-geographical cluster and set an example for how to coordinate activity, share learning, and improve quality of care in general practice.

Protected time to meet and to work on service development projects is a key part of the project, made possible by the additional clinical capacity provided by the fellows. The role of the overall lead GP for the project is critical to avoid duplication of effort, as many similar needs have been identified in the 6 practices, eg, improving cancer screening uptake and improving care of people seeking asylum and refugees. The protected time for professional development that the GP fellows have is another key feature of the scheme.

The Pioneer scheme is still at an early stage, but the host GPs involved already report a decrease in stress and renewed enthusiasm for their work. Patient benefits will take longer to demonstrate, but the scheme draws upon elements of other projects that have taken place in Deep End practices that have reported cost-effective patient benefits, such as the CARE Plus study $^{2}$ and the Links worker program. ${ }^{3}$

Key words: primary health care; general practitioners; disparities; physician workforce

Author affiliations, references, acknowledgements, information about funding support, and the supplemental appendix are available at http://www.AnnFamMed.org/content/15/3/277/suppl/DC1/. 